\title{
Direito ePraxis
}

Hacer genealogía de la experiencia: el método hacia una crítica a la colonialidad de la Razón feminista desde la experiencia histórica en América Latina

Doing genealogy of experience: towards a critique of the coloniality of feminist reason derived from the historical experience in Latin America

\section{Yuderkys Espinosa Miñoso ${ }^{1}$}

${ }^{1}$ Centro de Estudios de Género-INTEC, Santo Domingo, República Dominicana. E-mail: espinosayuderkys@gmail.com. ORCID: https://orcid.org/0000-0003-1141-2767.

Artigo recebido em 12/03/2019 e aceito em 10/07/2019.

\section{$(\mathrm{cc})$ EY}

This work is licensed under a Creative Commons Attribution 4.0 International License 


\section{Resumen}

En este trabajo acudo a la experiencia para interrogarla. Como testigo de treinta años del feminismo en la región, planteo preguntas claves que surgen tanto del método genealógico como de la crítica modernidad/colonialidad. El ejercicio me ha permitido profundizar en la crítica que ya he venido haciendo desde adentro y, desde hace ya algunas décadas, al feminismo conocido. Los problemas que se develan ya no se refieren solo al feminismo hegemónico, sino que encuentro una razón feminista eurocentrada actuando en la base de todo el campo feminista, incluyendo los espacios contrahegemónicos experimentados. Desarrollo una metodología que nombro como "genealogía de la experiencia", ello me permite concluir que hay una colonialidad de la razón feminista que permanece oculta tras el velo del compromiso con la lucha de las mujeres. El marco de América Latina y El Caribe, desde donde desarrollo el proyecto y desde donde escribo, es solo el caso desde donde me acerco a demostrarlo.

Palabras clave: Teoría feminista; Feminismo en América Latina; Colonialidad; Feminismo Descolonial.

\section{Abstract}

In this article I engage with and interrogate experience. As a witness of thirty years of feminism in the region, I pose key questions that arise both from the genealogical method and from the modernity/coloniality critique. The exercise has allowed me to deepen the criticism that I have been developing, for a few decades now, from within the feminism we know. The problems that are revealed are no longer found merely within hegemonic feminism, I rather find that the whole feminist field is grounded in a Eurocentric feminist reason, including the experiences in counter-hegemonic spaces. I develop a methodology that I have named as "genealogy of experience" that allows me to conclude that there is a coloniality of the feminist reason that remains hidden behind the veil of engagement with the women's struggle. The Latin American and Caribbean context, where I develop this project and I write, is only the case I have chosen to show the persistence of this feminist reason.

Keywords: Feminist theory; Feminism in Latin America; Coloniality; Decolonial Feminism. 
¿Cómo hemos llegado a ser las feministas que somos?

En este artículo me propongo un nuevo acercamiento al feminismo tal como lo he vivido y experimentado desde América Latina. Si bien para el abordaje recurro a la producción filosófica contemporánea y específicamente a los aportes de la crítica descolonial, lo que me anima no son objetivos meramente teóricos - si es que algo como esto existiera- sino urgentemente prácticos. Lo hago desde la convicción que toda acción se fundamenta en interpretaciones del mundo que a la vez son prescriptivas de mundo. Siendo así, estoy interesada en develar aquello que ha sostenido nuestras prácticas feministas y aquello a lo que nuestras prácticas políticas contribuye. El mundo al que con nuestro accionar estamos haciendo posible.

Se trata de responder la pregunta clave que nos propone el método genealógico y que al aplicarlo al campo feminista se traduce en: cómo hemos llegado a ser las feministas que somos. Cuáles son las condiciones de posibilidad que han permitido al feminismo creer en lo que cree, decir lo que dice, hacer lo que hace aun en un espacio determinado geopolíticamente por su condición de "tercer mundo", de región que arrastra consigo la herida colonial, como condición de ser lo que es hoy. A partir de estas preguntas se habilita la posibilidad de reconstruir algunas claves para pensar el feminismo en América Latina y su historia de dependencia. No feminismo latinoamericano, si no feminismo en América Latina, ya que no hay sino una razón feminista con pretensiones de universalidad a la que se ha acogido con tesón el feminismo regional. Si ante la afirmación de que el feminismo responde a la modernidad parecería que no se produce algún tipo de sorpresa, habrá que preguntar cómo hemos estado dispuestas a seguirlo en las regiones del mundo en donde la modernidad no puede sino revelarse como lo que es: racista, eurocentrada, capitalista, imperialista, colonial.

Quizás las mujeres, los géneros y las sexualidades despreciadas hayamos sucumbido a la idea - base de la teorización y el pensamiento feminista - de que todo pasado siempre ha sido peor para nosotrxs. Quizás el feminismo debería admitir, tal como lo ha hecho ya el feminismo de la igualdad (AMORÓs, 1997; 1990), que nuestra lucha no puede ser sino moderna, que no puede sino proclamar la modernidad como el tiempo histórico que nos permite liberarnos. Este argumento revela(ría), a todas luces, los intereses diferenciados 
entre el feminismo y las luchas antirracista, anti y descoloniales en la región. Permite develar la trama oculta de las luchas feministas y su compromiso con la colonialidad.

Así, en este trabajo me propongo adelantar la propuesta metodológica de una genealogía de la experiencia para el abordaje y el desarrollo de la crítica a lo que de antemano nombro como la colonialidad de la razón feminista. El marco de América Latina, desde donde desarrollo el proyecto y desde donde escribo, es solo el caso desde donde me acerco a demostrarlo.

\section{El proyecto de una crítica a la razón feminista moderna eurocentrada}

El proyecto se inicia a partir de la pregunta por el feminismo latinoamericano: ¿Cómo documentar las disputas de sentido y la construcción de hegemonías y contrahegemonías que de allí derivan? ¿De qué manera aportar a la construcción de una contramemoria que nos permita evidenciar los juegos de poder, las relaciones jerárquicas que ocultan y colaboran con la producción local de subalternidad dentro del "sur global", la fractura interna del "sujeto colonial"? Si Mohanty (2008a, 2009b) nos ha advertido del colonialismo discursivo de los feminismos del norte, la práctica activista subalterna nos ha demostrado el colonialismo interno, los dispositivos de control y las tácticas de producción y conservación de poder de una minoría dentro del campo feminista en América Latina. La herida colonial sangra más en unas que en otras. Los feminismos hegemónicos del norte han necesitado de la complicidad de los feminismos hegemónicos del sur para dar continuidad a la historia de colonización y dependencia. Es por esto que un análisis de los feminismos del sur y de su relación dependiente con los feminismos del norte necesita de un análisis complejo que permita desarmar el mito de la supuesta unidad interna de su sujeto "mujeres" y permita observar un campo vivo de disputa de sentidos en la América Latina posindependencias que termina resolviéndose a través de la imposición y la violencia simbólica y material hacia aquellas cuyos cuerpos están marcados por los procesos de racialización y de explotación continua, lo que he nombrado como "la otra de la otra" (ESPINOSA, 2010).

De allí surge la conciencia de la necesidad de hacer una genealogía crítica del presente de la política y el pensamiento feminista en América Latina que muestre lo 
doblemente ocultado por las tramas coloniales y poscoloniales, que muestre la colonialidad de la razón feminista. El proyecto busca denunciar - y así aportar a desmantelar - el compromiso del feminismo con los presupuestos de la modernidad y la manera en que contribuye a la tarea de su expansión. Esto es: la descolonización del feminismo. Para ello desarrollo una propuesta metodológica que se apoya, por un lado, en el método genealógico desarrollado por una tradición importante del propio pensamiento filosófico, dentro mismo de la modernidad. Si el método genealógico ha servido a las apuestas antiiluministas dentro de la propia modernidad occidental ¿puede servir al proyecto de mostrar los compromisos del feminismo con la ontología moderna eurocentrada aun en regiones como América Latina? ¿Cuáles son las implicaciones que esto tendría en términos de una crítica radical antirracista y descolonial? Partiendo de marco crítico producido por la teoría negra, de color, indígena, anti y descolonial en América Latina, la demostración va ligada a una mirada que impugna la modernidad occidental como proyecto máximo de evolución de lo humano, develándola en lo que en realidad ha sido: un proyecto imperialista, racista, de dominio y de muerte.

Por otro lado, me acojo a los desarrollos de la epistemología feminista y feminista negra y de color, y su propuesta de un conocimiento situado que parte de la experiencia. Para ello me centro en la revisión de los aportes de lo que se ha nombrado como "la teoría del punto de vista" como aquella que busca superar la pretensión del conocimiento científico de "hablar desde ninguna parte" (HARDING, 2012) y reviso las críticas que plantea Joan Scott (2001) a los usos de la experiencia como la base de nuestras explicaciones de manera de evitar caer en los mismos errores que documenta.

\section{Sobre el método genealógico y la idea de archivo}

Tradicionalmente el acercamiento de la filosofía latinoamericana a la construcción de una historiografía del pensamiento propio ha sido a través del método de Historia de las Ideas a las que nos convocaron varios de los más renombrados filósofos latinoamericanos, como Cerutti, Alberdi, Zea, Rodó, Bello (Cf. CASTRO-GÓMEZ, 2011, p. 245-247). Siguiendo este legado, una filósofa feminista como Francesca Gargallo (2004) se acogió a la construcción de 
una historia de las ideas feministas latinoamericanas en varias publicaciones de su proyecto "Las ideas feministas latinoamericanas". Aunque durante un tiempo he estado motivada a continuar esta tarea, sucedió que a medida que fui profundizando mi mirada y mis preguntas a la trayectoria del feminismo - que entonces nombré como latinoamericano -, fui encontrando claras diferencias entre lo que hacían desde la filosofía estos autores y, en particular, Francesca Gargallo desde una filosofía feminista latinoamericana, y lo que yo tenía en mente hacer. No pasó mucho tiempo hasta que, afortunadamente, en mi incursión en la literatura que estaban produciendo pensadores comprometidos con el giro descolonial, me encontré leyendo al filósofo Santiago Castro-Gómez (2011) en su “Crítica de la razón latinoamericana". Y fue allí en donde hallé las pistas de aquello que me interesaba hacer y que, de hecho, ya estaba haciendo sin proponérmelo. En el texto Castro-Gómez cuenta del llamado que hiciera otro gran filósofo colombiano, Roberto Salazar Ramos, miembro del "Grupo de Bogotá", quién convocó a desarrollar una arqueología de "lo latinoamericano", buscando encontrar los dispositivos a través de los cuales se han construido una serie de discursos que han dotado a América Latina de una especificidad y exterioridad con relación a la razón moderna occidental. Como nos hace saber el propio Castro-Gómez, su interés en esta investigación estuvo puesto en revisar "críticamente aquella familia de discursos que hizo posible la creación de una entidad llamada "Latinoamérica", dotada de un ethos y de una identidad cultural que, supuestamente, la distinguen de la racionalidad moderna europea" (CASTRO-GÓMEZ, ibid., p. 12). La pregunta que en definitiva guiará su trabajo no es ya aquello que caracteriza una identidad latinoamericana dada de antemano, sino más bien aquello que la hace posible, sus condiciones de posibilidad. ¿De qué forma se ha producido la identidad latinoamericana como una forma de ser y de pensar? ¿Cuál ha sido el papel de la filosofía en este proceso? Para responder a estas preguntas, Castro-Gómez se propone observar la producción del pensamiento filosófico en América Latina no con el objetivo de construir una "historia de las ideas" a la manera en que ha sido propuesto por la filosofía latinoamericanista, sino con el fin de desarrollar una "genealogía localizada de las prácticas" (Ibid., p. 245-247) que permitan develar críticamente la manera en que la filosofía en América Latina ha contribuido a producir la idea de lo propio "latinoamericano". 
Para Castro-Gómez, la tarea genealógica está ineludiblemente ligada a la tarea ya no tanto de encontrar lo que nos unifica, cuanto mostrar los antagonismos, los dilemas, los juego de poder, "las rupturas, los vacíos, las fisuras y las líneas de fuga..." (Idem, p. 117). En su estudio riguroso de la obra del Michel Foucault, Castro-Gómez observa cómo la tarea genealógica puede sernos útil al propósito de escudriñar nuestro presente para determinar las contingencias históricas y las estrategias de poder que lo ha hecho posible. Así, el filósofo colombiano nos muestra la genealogía al modo en que Foucault lo retoma del proyecto Niestcheano, como ontología crítica del presente. Encuentra y nos descubre la genealogía desarrollada por Foucault como un método efectivo que permite una nueva

forma de acercarse filosóficamente al problema de la modernidad, en donde antes que des-cubrir la "verdad" de sus promesas inherentes (libertad, igualdad, fraternidad), lo que se busca es mostrar las tecnologías de dominio que coadyuvaron a su fabricación, así como las formas diversas en que tal verdad constituye nuestra subjetividad contemporánea (CASTRO-GÓMEZ, 1998, p. 3)

De tal forma, el autor se dispone a mostrarnos la utilidad del método genealógico para develar la colonialidad en América Latina. Su estudio riguroso permite observar las bases ontológicas ilustradas sobre la que se han asentado los ideales de progreso y modernización sostenidos por las élites blanco-mestizas en los países latinoamericanos a partir de la experiencia concreta en Colombia (CASTRO-GÓMEZ, 2005; 2009). Su proyecto retoma así la apuesta foucaultiana en la medida en que ella nos ayuda a "levantar una cartografía de las fuerzas que nos constituyen en lo que somos" (CASTRO-GÓMEZ, 2011, p. 256) y develar de este modo la colonialidad.

Siendo que el método genealógico implica una pregunta sobre los hechos del presente de modo de identificar los intereses, los condicionamientos históricos y culturales que los han determinado, la voluntad de poder que los ha producido, éste puede ser efectivo en la producción de un pensamiento crítico atento a develar la economía política de verdad que legitima la red de significaciones y prácticas del presente. Es por esto que se hace necesario indagar las prácticas y su efectividad: qué es lo que realmente hacemos cuando hablamos o cuando actuamos. Cambiar la pregunta acerca de la identidad a una pregunta sobre lo que hacemos, las prácticas que nos hacen ser lo que somos. La investigación sobre las prácticas nos lleva a preguntarnos por lo que es una práctica, cómo funciona, cuáles son las reglas que la instauran. Hacer genealogía nos permite distanciarnos 
del presente para mirar las condiciones de posibilidad que nos constituyen. Mirar esos $a$ priori para problematizarlos y desnaturalizarlos. Trazar la historia de las prácticas para desnaturalizarlas, para observar cómo y en qué momento han surgido y por qué (CASTROGÓMEZ, 2015).

Inspirada por estas premisas y las preguntas a que nos convoca el método genealógico fue entonces que llegué a formular correctamente las preguntas para observar y analizar el feminismo en América Latina: ¿Cómo es que hemos llegado a ser las feministas - "mujeres adelantadas y superadas de nuestro tiempo" - que pretendemos ser? ¿Qué es lo que hacemos las feministas en América Latina cuando convocamos a una marcha por "el derecho al aborto", cuando gritamos "mi cuerpo es mío" o "libertad en la casa y en la plaza"? ¿Qué hacemos las feministas cuando presionamos a las instituciones y al Estado para aprobar una ley por "la igualdad de género", cuando abrimos espacios en la universidad y pedimos que las mujeres entren a ella masivamente, cuando armamos un programa de estudio en género y sexualidad, cuando hablamos de derechos reproductivos, cuando hacemos un discurso en/ante las Naciones Unidas, o formulamos y desarrollamos proyectos para "mujeres populares", o desarrollamos campañas en contra del acoso callejero? ¿Qué es lo que hacemos las feministas cuando decimos lo que decimos, cuando hacemos lo que hacemos? ¿Qué es lo que hacemos las feministas en América Latina cuando hacemos y decimos? Y fue de ahí que llegué a formular la idea de la existencia de "una razón feminista" universal y eurocentrada. Porque al volver a mirar desde estas preguntas lo que pude documentar es que no existe nada tal como una historia de especificidad en el feminismo que desarrollamos, sino más bien una historia de la voluntad por no diferenciarnos, por no apartarnos de las teorías, las apuestas y las consignas del feminismo producido en los países centrales. Un esfuerzo por ajustarnos a las teorías producidas en EEUU y Europa, de modo que se haría entrar en ella a las mujeres de los contextos más disímiles, atravesados por la colonialidad.

Intentar explicar el presente feminista en América Latina - sus dilemas, contradicciones, disputas, ejes de preocupación, estrategias políticas, discursos y prácticas me permitió reparar en una suerte de razón feminista compartida, una serie de principios sobre los que nos hemos asentado las feministas de todos los tiempos y de las más diversas corrientes contemporáneas tanto en Estados Unidos como en Europa como en América 
Latina, Asia o África. Una serie de principios que contribuyen a la producción del relato: nosotras, las mujeres; nosotras, las que siempre hemos sido dominadas. Y su contracara: nosotras, las superadas; nosotras, las mujeres libres dueñas de nuestro destino que llegamos a ser gracias al feminismo ( $y$, con ello, gracias a la modernidad).

Me he propuesto entonces repasar los dilemas y los límites de las prácticas teóricopolíticas producidas, sostenidas y alimentadas por el feminismo y los movimientos sociosexuales contemporáneos, vistos desde el contexto particular latinoamericano y su historia de colonialidad. El proyecto genealógico busca indagar los discursos a los que hemos adherido sobre la sexualidad, el género, el sujeto sexo-genérico, y las maneras en que hemos aplicado estos discursos para pensar "lo latinoamericano" como un espacio globalizado en busca de su integración a lo (verdaderamente) humano. Lo que propongo es un ejercicio crítico que permita tomar conciencia de cómo hemos llegado a ser las feministas y/o el sujeto sexo/genérico "libre, transgresor y adelantado de nuestro tiempo" que pretendemos ser. Mostrar esa "economía política de la verdad" (CASTRO-GÓMEZ, 2011, p. 12) que se evidencia en las prácticas políticas y discursivas en torno al género y la sexualidad (patriarcado y régimen heterosexual) que hemos contribuido a producir en la medida de nuestra fe ciega y contribuciones a unos postulados feministas que se presentan como universales. Me interesa detenerme en estos postulados para denunciar las formas de regulación, jerarquización, legitimación de unas formas de comprensión sobre otras.

Para poder hacer esta crítica del presente de nuestro feminismo es necesario también acudir a la arqueología. Hacer de archivista, de cartógrafa

[...] de nuestra memoria mostrando a viejos testimonios como síntomas del presente". Construir "archivo audio-visual" y bregar con la más amplia variedad de documentos disponibles, así como con las "prácticas mudas, conductas de los costados, discursos heterogéneos y estar dispuesta a "excavar y rastrear en las profundidades, saca a luz lo que está oculto" (GONÇALVEZ, 2000, p. 1-2).

En definitiva, como señala el propio Foucault, se trata de recoger el conjunto de reglas que funcionan para un grupo de personas dentro de un período determinado de modo de poder determinar (1) "los límites y las formas de la decibilidad": lo que se puede o no decir; (2) "Ios límites y las formas de conservación": qué discursos son tomados en cuenta y cuentan como parte importante de la memoria y cuáles pasan desapercibidos sin "dejar huella"; (3) "los límites y las formas de la memoria tal como aparecen en las 
diferentes formas discursivas": Cuáles discursos son reconocidos como válidos y cuáles como discutibles o inservibles; (4) "Ios límites y las formas de reactivación": ¿cuáles son los discursos que se intentan reconstruir?; (5) "Los límites y las formas de la apropiación": “¿Qué individuos, grupos, clases tienen acceso a un tipo determinado de discursos?" (FOUCAULT, 1991, apud GONÇALVEZ, 2000, p. 3).

Si es cierto que la genealogía se trata de

[...] percibir la singularidad de los sucesos, fuera de toda finalidad monótona; encontrarlos allí donde menos se espera y en aquello que pasa desapercibido por no tener nada de historia - los sentimientos, el amor, la conciencia, los instintos -, captar su retorno, pero en absoluto para trazar la curva lenta de una evolución, sino para reencontrar las diferentes escenas en las que han jugado diferentes papeles [...]" (FOUCAULT, 1992, p. 2)

entonces, ya me había ido preparando para la tarea, estaba de hecho YA haciendo la tarea hace rato. La había iniciado sin saberlo desde hacía un largo tiempo cuando, por alguna razón, comencé a construir meticulosa y obsesivamente un archivo de las prácticas y las prácticas discursivas del feminismo vivido y experimentado. Motivada por esta obsesión de archivista comencé a escribir hace ya un buen tiempo, y la práctica escritural sirvió para grabar en mi memoria y en la memoria colectiva cada momento dentro de la política feminista vivida, primero localmente, $y$, en la medida en que formé parte de un movimiento más internacional, regionalmente. Fue un ejercicio compartido por varias de aquellas con las que he caminado ${ }^{1}$. Armé un archivo digital y otro en papel donde fui guardando textos iniciales publicados aquí y allá en espacios virtuales, blogs, panfletos, revistas no especializadas; así como fotografías e imágenes de nuestras actividades y borradores a medio hacer nunca publicados. Pero hay algo más que escapa a ese archivo físico, se trata del ejercicio sistemático de fijar en el recuerdo y de manera consciente una memoria de afectos, de imágenes, de sentimientos, pero también de palabras dichas y silencios, de análisis compartidos en jornadas de reflexión política o tardes de (re) encuentro con las amigas y de discusiones acaloradas con mis antagonistas de entonces y de ahora.

A todo ello he apelado en el ejercicio de interpelación a la práctica feminista experimentada. He acudido a la idea de experiencia y de testigo activo para la construcción

\footnotetext{
${ }^{1}$ Muchas son las compañeras y hermanas con las que he compartido el rol de testigo crítico de los vericuetos de la política feminista en América Latina y en el norte global. No podría mencionarlas a todas pero sin lugar a dudas activistas y pensadoras del feminismo autónomo, del movimiento lesbofeminista y de mujeres negras e indígenas en América Latina han sido parte de esta historia.
} 
de mi archivo. Como una activista implicada activamente en el hacer y en los debates del feminismo en América Latina me he preguntado si era posible acudir a mi memoria histórica, a los cerca de 30 años de recorrido y observación implicada dentro de momentos cruciales de la historia de mediano plazo del feminismo regional. Construí mi archivo con las notas de las reuniones a las que acudí, las actividades que ayudé a organizar, las discusiones de las que fui parte, las reflexiones que de allí surgieron y que se acumulan en ensayos, notas, artículos publicados e inéditos. Con las mil y una historias que guardo en la memoria y de las que he sido testigo participante o no, pero que he escuchado en diferentes versiones por parte de quienes allí estuvieron. Hay también una memoria corporal y visual que acompaña los discursos, sensaciones de alegría, de dolor, de victoria o de derrota, de expectación, incredulidad o certezas. En síntesis, me he propuesto construir y proponer la posibilidad de hacer una genealogía de la experiencia del feminismo en América Latina. Usar la propia experiencia como documento sustancial y fundamental de mi archivo y acudir, a modo de corroboración, a otras fuentes: artículos, ensayos, grabaciones en video y en audio, fotografías producidas por otras activistas y pensadoras que también han sido parte de este recorrer y transitar por el feminismo en América Latina durante el tiempo que me ha tocado vivir y que intento documentar.

Para fundamentar esta elección metodológica he acudido a revisar la crítica que ha sido producida dentro del feminismo y fuera de él a la pretensión de objetividad del método científico. Y quiero observar la manera en que la teoría feminista del punto de vista puede ayudarme a encontrar los argumentos que validen mi uso de la experiencia como archivo desde donde puedo hacer esta genealogía crítica del presente feminista y mostrar su colonialidad.

3. Del uso de la experiencia para construir el archivo de una genealogía de la razón feminista en América Latina.

Como sabemos, la epistemología feminista en su conjunto, y, en específico, la tradición producida por el feminismo negro y de color en su crítica al método científico, han propuesto y tematizado la "experiencia" de las mujeres y de las mujeres negras y de color 
como base válida para la producción de conocimiento (SMITH, 2012; HARDING, 1987; HARSTSOCK, 1983; HILL COLLINS, 1999). En concreto, ha sido la llamada perspectiva del "punto de vista", desarrollada por la epistemología feminista blanca y retomada por la teoría feminista negra y de color la que se ha ocupado de desarrollar una crítica a los métodos de producción de conocimiento por parte de la ciencia moderna y han propuesto en su lugar el uso de la experiencia como forma efectiva de construcción de saber. Mientras las primeras, se han centrado en la crítica al androcentrismo y la pretensión de objetividad por parte del método científico, las segundas, o sea, las feministas negras y de color, desarrollan una crítica implacable al universalismo de la categoría mujeres de la teorización feminista clásica, señalando que lo que cuenta como teoría feminista es apenas un "punto de vista" producido por las mujeres blancas que han accedido a la formación universitaria gracias a sus privilegios de clase y raza (HOOKS, 2004). Algunas teóricas del feminismo negro se han propuesto entonces la producción de una teorización propia como un punto de vista particular que parte de la experiencia de las mujeres negras (HILL COLLINS, 1999). Algo parecido ocurrirá en las dos últimas décadas en América Latina cuando la reaparición de un fuerte movimiento continental anticolonialista y descolonial pondrá en entre dicho la versión de la historia y los conocimientos producidos por las ciencias sociales en manos de intelectuales e investigadores de origen blanco-mestizo. Será así que aparecerá como una de las tareas importantes para estos movimientos y para el feminismo descolonial la producción de una voz y una interpretación propia (CARNEIRO, 2001; MENDOZA, 2010; CUMES, 2009; PALERMO, 2008).

La crítica del feminismo negro, de color y más recientemente descolonial, terminó haciendo al interior del feminismo la misma denuncia que la epistemología feminista hiciera a la producción científica occidental de conocimiento: encubren de objetividad y universalidad lo que es en realidad un punto de vista parcializado ya que surge de una experiencia histórica y unos intereses concretos (ESPINOSA, 2014). Lo cierto es que la teoría del punto de vista por sí sola no garantizó superar la traba ni del esencialismo universalista de la categoría mujer, ni, por tanto, del racismo, el eurocentrismo y la colonialidad de la teoría feminista más difundida. Tal como lo señala Harding (2001, p. 111-112), recordando varias de las críticas que le han hecho pensadoras como Haraway: "la epistemología del 
Punto de vista feminista, como otros tipos de teorías feministas socialistas, es culpable de este error teórico y político".

Sin embargo, a pesar de estos problemas, no podemos dejar de admitir los aportes de esta teoría para la construcción de un método de análisis que fundamenta la experiencia como fuente de conocimiento. Propuesta inicialmente por Nancy Harstsock (1983) y Dorothy Smith $(1974,1987)$, esta teoría argumenta inicialmente que el punto de vista de las mujeres ofrece explicaciones de la vida social en su conjunto mucho más amplias que las que suelen poder dar los hombres, dado la mayor visibilidad que les proporciona a las mujeres las actividades que les son asignadas dentro de la división sexual del trabajo. Mientras para la mirada masculina una parte importante de las actividades sociales no son observadas o tomadas en cuenta porque son vistas como tareas de orden "natural", de reproducción de la vida y cuidado; las mujeres, responsables de estas actividades, pueden verlas y desde ahí observar también aquellas que son elaboradas por los varones actividades consideradas abstractas - y que gozan de valor social. Es lo que Harding (2001, p. 128) nombra como una "conciencia bifurcada" que las investigadoras feministas ponen en acto a través de sus estudios y análisis. Así las epistemólogas del punto de vista feminista señalarán que son más adecuados los estudios que parten preguntándose sobre el mundo y las actividades de las mujeres, porque nos permiten una mirada desde abajo hacia arriba, ya que esta perspectiva nos permite tener una mirada más amplia, completa y menos distorsionada de lo social.

Así, si el orden social es una matriz de poder en donde raza, clase y género se superponen y codeterminan, la perspectiva del punto de vista feminista en la investigación permitiría volver más visible la manera en cómo actúa la matriz al partir de cuestionar la experiencia de quienes se encuentran en la escala más baja de privilegio. De tal forma "lo que es una desventaja desde el punto de vista de la opresión, puede convertirse en una ventaja desde el punto de vista de la ciencia" (HARDING, 2001, p. 132). Esta idea recuerda y me parece emparentada a la idea de "doble conciencia" propuesta por Do Buois como la perspectiva privilegiada del mundo que tendría el sujeto racializado en la medida de su cohabitar el mundo subalterno, sometido a la opresión, y su incursión como tal en el mundo de las clases dominantes, el mundo de los blancos. Este habitar produce la posibilidad del 
surgimiento de una doble mirada, una mirada alternativa (second-sight) que les permite ser consciente de su lugar subalterno (DU BOIS, 1989[1903], p. 2-3).

es una sensación peculiar, esta doble conciencia, esta sensación de mirarse a uno mismo siempre a través de los ojos de los demás, de medirse el alma con el rasero de un mundo que observa con un desprecio y una piedad divertidas. Uno siempre siente su dualidad, - americano, negro; dos almas, dos pensamientos, dos luchas no reconciliadas-. (DU BOIS 1989([1903]), apud SOMMER, 2001, p. 85)

Si Du Bois se lamenta de esta conciencia doble, bifurcada, que nos hace "perder el enfoque" (SOMMER, 2001, p. 87), desde la teoría del punto de vista esto más que un obstáculo se vuelve una posibilidad de una mirada más acabada y heterogénea del mundo. De allí puede surgir una crítica más radical y comprometida con la transformación social, en la medida que evidencia lo que queda oculto por las tramas de poder y, en el caso de los contextos de los países del sur global, el colonialismo interno. Ahora ya sabemos: explicar el mundo y los acontecimientos desde el punto de vista de quien solo ocupa un lugar privilegiado, nos da un entendimiento parcial y distorsionado que puede ser saldado gracias a la mirada y la experiencia doble de quien ocupa un lugar subalterno.

Una podría llegar a decir, como conclusión lógica, que la mirada subalterna es una mirada doble, contradictoria, conflictiva, paradojal, impura...y que justamente por eso nos otorga mayor fuente de conocimientos. Pienso entonces por qué la mirada producida por el feminismo blanco y blanco-mestizo, ha sido siempre incompleta, iluminando solo una parte de la trama de cómo opera la opresión. Esta mirada incompleta, no solo no permite dar cuenta de la opresión de una serie de sujetxs en posición de desprivilegio, sino que no permite ver la complejidad de la matriz de opresión en su conjunto, no permite ver las relaciones intrínsecas entre los proyectos de dominación. En acuerdo con esto, quiero introducir una pequeña gran distorsión a la perspectiva del punto de vista feminista. Si Mohanty celebra el privilegio epistémico de aquellas que ellas se encuentran en la escala más baja de la estructura social y desde allí nos dan pistas para observar cómo esta funciona en su conjunto, y hemos de aceptar la crítica del feminismo negro y de color de que en la base de la pirámide del poder encontramos a la mujer racializada, entonces la sujeta de este punto de vista privilegiado no es cualquier mujer, sino una mujer subalterna, que en América Latina es indígena y afrodescendiente, campesina, desterritorializada o popular. 
Será entonces que el punto de vista que quiero producir a partir de mi experiencia de paso por el feminismo en América Latina, es un punto de vista que se produce desde ser/habitar un cuerpo sometido al empobrecimiento, al despojo y la negación sistemática de su capacidad de producir saber, crítica y proyecto de futuro. Es desde la experiencia de provenir de un pueblo deshumanizado, sometido a la servidumbre y a la negación de sí mismo desde donde intentaré responder las preguntas que planteo al feminismo regional. La idea de una genealogía de la experiencia parte por reconocer el lugar de enunciación desde donde se escribe. La pregunta sobre cómo hemos llegado a ser las feministas que somos y qué es lo que hacen las feministas en América Latina cuando hacen lo que hacen, será respondida desde la sujeta producida entre mundos: esa a la que el barrio de gente negra empobrecida la habitará por siempre como marca de origen; esa que vio el mundo de los blancos ricos en la televisión, en el cine, en el patrón, en el grupo de chicas blancamestizas de clase alta que se burlaban de ella en la escuela, esa que al acceder a la universidad y al feminismo - como lugares privilegiados definidos en términos de raza y clase -, pudo terminar de conocer esa peculiar sensación enunciada por Du Bois "de mirarse a uno mismo siempre a través de los ojos de los demás".

Pero no confundir: la que hace genealogía usando su experiencia como archivo deberá evitar el error de usarla como fundamento o como prueba, como aquello que permite fundamentar la explicación. Haciendo caso a las advertencias de Scott (2001) sobre sus "malos usos", la experiencia como archivo debe convertirse en aquello que necesita ser explicado: ¿cómo hemos llegado a ser las feministas que somos, las mujeres adelantas que pretendemos ser?, es la pregunta que le hago al feminismo experimentado. Pero también hay una pregunta oculta y personal: ¿cómo fue que aprendí a leerme fundamentalmente como mujer parte de una comunidad de mujeres a nivel global? ¿Cómo fue que construí una historia de mi misma a partir de esa categoría fundamental para el feminismo? ¿Cómo fue que no pude durante mucho tiempo dar significado a todo un resto de mi experiencia del cual no daba cuenta el discurso feminista? En el caso de la genealogía del feminismo en América Latina y la manera en que (re)produce una razón eurocentrada, acudir a la experiencia de tres décadas de activismo me permite cuestionarla, interrogarla, criticarla. Cómo se establece la diferencia entre la "sujeta feminista adelantada" y la que queda desdibujada como atrapada por la ignorancia, la falta de conciencia sobre su propia 
opresión; cuales son las verdades que hemos aceptado y qué definen nuestras prácticas, cómo estás operan, cómo y de qué maneras el feminismo constituye sujetos que ven el mundo de una determinada manera y que actúan sobre él.

4. Cómo y desde dónde argumento que hay una razón feminista moderna occidental y que ésta tiene un compromiso con la colonialidad.

Las ideas fuerza que quiero afirmar y proponer como conclusión de mis indagaciones y, a la vez, como hipótesis a ser confirmada o desmentida en lo sucesivo, es que (1) hay una razón feminista universal, y (2) que esta razón se ha caracterizado por su compromiso con la modernidad $y$, por consiguiente, con su cara oculta la colonialidad y el racismo que la define. Así, por colonialidad de la razón feminista entiendo, en principio, una serie de prácticas y prácticas discursivas - en el sentido foucaultiano - que han sido acordadas y desarrolladas por las feministas de cualquier tendencia y por medio de las cuales éstas han contribuido a la producción de un sujeto universal "mujer/mujeres". Se trata de una serie de discursos sobre este sujeto, que más allá del debate y la aceptación o no de sus diferencias internas, mantiene ciertos acuerdos básicos de interpretación del lugar de este sujeto dentro de lo social, así como una serie de prescripciones sobre las prácticas para lograr su liberación. La teorización feminista ha producido y desplegado una representación e imagen de "la mujer" - más allá de cualquier diferencia, espacio y tiempo - como aquella que está siempre en estado de sujeción, menor poder y jerarquía con "el hombre" - también universal. Asumiendo el dispositivo de la sexualidad y contribuyendo de forma paradigmática a la producción de una tecnología de "género", sin cuestionar las bases ontológicas en cuya aparición ambos son posibles, las feministas han dado continuidad al mito moderno y a su razón eurocentrada.

Aquí es importante el concepto de "razón" y cómo lo estoy entendiendo. Por razón estoy aludiendo a cuatro cuestiones fundamentales que han sido sustanciales a la filosofía y la modernidad y, por tanto, a la colonialidad:

1. La pretensión de llegar a un conocimiento verdadero del mundo a través de explicaciones confiables que permitan encontrar una salida al estado de tutela. En esta 
acepción la "razón" - la verdadera, aquella en estado de madurez - es aquella que está ligada irremediablemente al advenimiento de la llustración. "[L]a modernidad y la racionalidad fueron imaginadas como experiencias y productos exclusivamente europeos", nos recuerda Quijano (2000a, p. 6). Servirse de la razón implica que "el hombre" es capaz por primera vez de producir su propio entendimiento del mundo "sin la dirección de otro" (KANT, 1996, p. 53). Así, para Kant

La ilustración es la liberación del hombre de su culpable incapacidad. La incapacidad significa la imposibilidad de servirse de su inteligencia sin la guía de otro. Esta incapacidad es culpable porque su causa no reside en la falta de inteligencia sino de decisión y valor para servirse por sí mismo de ella sin la tutela de otro. iSapere aude! iTen el valor de servirte de tu propia razón!: he aquí el lema de la ilustración. (KANT, [1784] 1994, p. 1)

Si para Kant la ilustración es un tiempo de llegada a la madurez, esta "madurez" refiere a que "el hombre" se opone a la autoridad de la tradición y en su lugar instituye un régimen que somete toda creencia al "tribunal de la razón" para que sea juzgada de acuerdo a sus principios universales, principios que a través del estudio y el dominio de la naturaleza conducirán al progreso inevitable y la salida de la ignorancia (CASTRO-GÓMEZ, 2010, p. 22).

Si bien la teoría y la investigación feminista se han construido en contraposición al método positivista cartesiano que se presenta como neutro, incontaminado, capaz de descubrir las leyes verdaderas que rigen el orden natural y social, lo cierto es que, para poder ganar un lugar dentro de la producción de una verdad sobre "las mujeres", el género y la sexualidad, el feminismo ha tenido que recurrir a formas de validación de conocimientos, aceptando y siendo parte del dispositivo saber/poder mediante el cual se establece una frontera entre lo que es un saber legítimo y lo que no lo es.

Al margen de ello, lo cierto es que el feminismo y las feministas se han posicionado como poseedoras de un conjunto de verdades que desafía el saber común sobre la realidad social y sobre el sujeto "mujeres", sujeto que ha ayudado a definir y desde donde establece su diagnóstico del mundo. Las feministas están convencidas que - por el hecho de ser poseedoras de esta verdad sobre las mujeres -, ellas, más que nadie, están en capacidad de establecer el programa liberatorio que permitirá a las mujeres escapar de su estado de sujeción histórica. En su convencimiento las feministas han desarrollado una agenda global 
para la liberación e igualdad de las mujeres que predican e imponen al resto del mundo y en particular, a las mujeres de los países que consideran menos avanzados, a través de diferentes medios. Es lo que ha sido denunciando por las mujeres del tercer mundo como un "afán salvacionista" que no es otra cosa que imperialista.

2. Cuando hablo de razón, la uso también en el sentido que la usa Hegel en su Primer programa de un sistema del idealismo Alemán cuando habla de la "mitología de la razón" como "un sistema orgánico de creencias firmemente asentado en el ethos de la comunidad, capaz de vincular a los individuos y dar sentido a la acción colectiva." (CASTROGÓMEZ, 2011, p. 132). Una vez que hemos aprobado la necesidad de deshacer el lazo comunal orgánico que daba sentido a la comunidad originaria vista como la fuente del atraso por parte de la modernidad, las feministas hemos llamado a la construcción de comunidades nuevas de mujeres liberadas de la carga de la tradición. Las feministas hemos inventado la "comunidad de las mujeres" con el fin de dar sentido a una lucha y una vida común.

3. También estoy pensándola como racionalización en el sentido weberiano, es decir, en palabras de Santiago Castro-Gómez: "la organización metódica de la vida y el sometimiento de la conducta humana a un conjunto específico de reglas con el fin de obtener unos resultados esperados" (Ibid., p. 53). Así, las feministas al interior de las comunidades que desarrollamos y que pretendemos ser, prescribimos una serie de prácticas, somos una serie de prácticas que se rigen por una serie de prescripciones sobre lo que sería "la mujer liberada", el sujeto de la liberación del género y la sexualidad. Las ideas y las verdades feministas no solo crean una idea de mundo y produce sujetos. Al igual que cualquier otro discurso, contiene prescripciones implícitas sobre qué significa ser una mujer de nuestro tiempo, o sea una mujer en busca de su autodeterminación.

4. Finalmente, cuando hablo de "la razón feminista", estoy aludiendo en realidad a una forma de crítica. La razón del feminismo responde al gesto prepotente e imperialista de la razón moderna como aquella que se autoproclama como la única verdadera razón existente, aquella en su máximo desarrollo evolutivo, o sea la que se desarrolla dentro de su propio tiempo histórico y dentro de un espacio específico: Europa. En la denuncia que autores como Dussel (2000) y Quijano (2000a) realizan a esta operación lo que occidente ha nombrado como razón en realidad es efecto del eurocentrismo, un programa que pretende 
anular y desconocer todas las otras formas de pensamiento como formas de conocimiento y racionamiento válido.

Si para Dussel la modernidad es un fenómeno posible en todas las culturas y en todas las épocas históricas, es gracias a la empresa colonial que Europa logró imponerse sobre los pueblos y civilizaciones conquistadas y así, definirse a sí misma como lo nuevo y más avanzado de la especie (QUIJANO, 2000b). Según este mito, la humanidad evoluciona unilineal y unidireccionalmente de un estado de naturaleza a un estado máximo de desarrollo cultural, cuya culminación es la civilización europea u occidental. La idea de raza es la piedra angular que sostiene todo el andamiaje que propone a Europa como superior y ejemplo a seguir. El éxito, pues, de Europa Occidental en imponerse como el centro de mundo moderno, consistió en desarrollar al mismo tiempo el eurocentrismo como rasgo compartido de la empresa colonialista e imperialista aunado al desarrollo de la raza como forma de clasificación mundial (colonialidad), lo que permitió a los europeos el desarrollo de "una nueva perspectiva temporal de la historia y re-ubicaron a los pueblos colonizados, y a sus respectivas historias y culturas, en el pasado de una trayectoria histórica cuya culminación era Europa" (QUIJANO, Ibid., p. 210).

En este mismo sentido, Mario Blaser (2013) propone pensar la modernidad como el estado del ser que se logra a partir de la puesta en escena del mito moderno compuesto de tres hilos básicos: a) la gran separación entre naturaleza y cultura, b) la diferencia colonial entre modernos y no-modernos, y c) una temporalidad lineal unidireccional que discurre desde el pasado hacia el futuro". Hay ejemplos varios de cómo la razón feminista se apega a estos preceptos en su interpretación del mundo. Demostrar la razón feminista como razón moderna eurocentrada implicará detenernos a observar cómo ellos se reproducen en nuestras prácticas teórico-discursivas, en nuestras prácticas políticas y en nuestros proyectos de futuro.

Diré que cuando hablo de la razón feminista como una razón moderna eurocentrada, me acojo a las revisiones realizadas por estos autores en el sentido aquí expuesto. El feminismo como proyecto global que universaliza una interpretación sobre la sociedad y la condición de las mujeres - mujeres como sujeto también universal -, se evidencia en su compromiso con la colonialidad y con la modernidad. La etapa neoliberal iniciada a finales de 1980 - vale decir, momento en el que se inicia mi incursión en el 
feminismo latinoamericano y por tanto a partir del cual desarrollo mi proyecto de una genealógica crítica del feminismo en América Latina -, ha sido fundamental para terminar de concretarse la expansión de estas ideas e ideales del/los feminismos. La investigación en curso dará cuenta de ello.

\section{Reflexiones finales}

Al inicio del recorrido que les propuse me preguntaba si el método genealógico podía servir al proyecto de mostrar los compromisos del feminismo con la ontología moderna eurocentrada, y cuáles serían las implicaciones que esta crítica tendría en términos de una crítica radical antirracista y descolonial. Creo que en los párrafos anteriores he aportado elementos generales para sustentar su eficacia a estos fines. Queda, sin embargo, la tarea necesaria de aplicar el método a diferentes elementos y aspectos concretos de la práctica feminista contemporánea, a modo de develar paulatinamente y sin dejar lugar a dudas la manera en que la razón feminista eurocentrada determina y conforma la política feminista en América Latina, y más allá de ella, a nivel global.

En algunos trabajos ya publicados he avanzado en ello acudiendo al método genealógico propuesto de la experiencia, para pensar los movimientos de liberación sexogenérica y queer identitario (ESPINOSA, 2012; 2015), y específicamente el movimiento de lesbianas en América Latina (ESPINOSA, 2016). Igualmente he aplicado este modelo para intentar responder explicitar e indagar en las dificultades de encuentro entre el feminismo y los movimientos antirracistas en el continente (ESPINOSA, 2017). En mis cursos sobre metodología de investigación feminista descolonial he hablado y promocionado la genealogía como un método no sólo para develar los compromisos del feminismo contemporáneo con la modernidad y su cara oculta - la colonialidad -, sino para producir formulaciones nuevas a los problemas clásicos plateados por el feminismo. El método ha mostrado su eficacia para complejizar el abordaje de temáticas muy amplias y variadas. Estos ejercicios van permitiendo intervenir en la red de significaciones y consensos más preciados de la razón feminista eurocentrada, mostrando la parcialidad y la 
sobredeterminación de muchas de las verdades validadas y universalizadas por la teorización y la política feminista.

La tarea de preguntar cómo hemos llegado a ser lo que somos, a creer lo que creemos, a decir lo que decimos, a hacer lo que hacemos va abriendo la puerta para pensar los pilares sobre los que se sostienen las prácticas feministas de las que hacemos parte. Alumnas, exalumnas y colegas están interrogando la historia y el presente glorioso del feminismo hegemónico mostrando como mucho de sus hitos responden a una historia de las luchas, los deseos y los triunfos de un reducido número de mujeres privilegiadas gracias a los grupos de origen de donde provienen. Un ejemplo de ello es cómo lo que se festeja como la obtención del voto por parte de las mujeres a nivel mundial, fue la fecha en que un grupo de mujeres letradas y de las elites blancas y blanco-mestiza lograron hacerlo; la gran mayoría de mujeres perteneciente a grupos despreciados de la nación solo obtuvieron el voto cuando sus grupos lo obtuvieron.

Trabajos académicos recientemente publicados, inéditos o en producción, así como manifiestos y publicaciones que circulan a través de las redes sociales, más allá de que se planteen expresamente hacer genealogía, ayudan a su construcción, al interrogarse por las condiciones de posibilidad del presente político al que asistimos: ¿cómo es que la lucha por la legalización del aborto llegó a ser el centro de la política feminista en América Latina y a nivel global? ¿Cómo es que la violencia interpersonal entre varones y mujeres se volvió el foco de la interpretación feminista de la violencia hacia las mujeres? ¿Cuáles han sido los resultados de una interpretación de esta violencia únicamente en clave de género? ¿Cómo es que se produjo, se conformó y se universalizó la idea de una huelga de mujeres como la estrategia de movilización del Día Internacional de la Mujer? ¿Quiénes la impulsaron, a través de qué mecanismos, qué grupos se sienten convocados y cuáles quedan fuera de la convocatoria ${ }^{2}$ ¿Cuáles son los vínculos entre las agendas y los enfoques de las políticas públicas hacia las mujeres de nuestros países y las políticas de ayuda al desarrollo y la

\footnotetext{
${ }^{2}$ El 8 de marzo del 2017, a propósito del primer llamado a huelga de mujeres, un grupo de organizaciones y pensadoras activistas redactamos, firmamos y publicamos, a través de las redes sociales. la reflexión "Algunas reflexiones sobre metodologías feministas: A propósito del llamado a un paro internacional de mujeres el 8Marzo". Disponible en: https://www.facebook.com/notes/yuderkys-espinosa-mi\%C3\%B1oso/algunasreflexiones-sobre-metodolog\%C3\%ADas-feministas-a-prop\%C3\%B3sito-del-llamado-a-un-p/619692941557176/
} 
cooperación internacional? ¿A qué grupos termina beneficiando? ¿ A qué ideal de mujer y a qué modelo de mundo contribuyen $?^{3}$

De a poco vamos dando puntadas hacia nuevas narrativas e interpretaciones que permiten descentrar el clásico sujeto normativo del feminismo, a la vez que agrietamos el armazón teórico conceptual y argumentativo producido por éste. A través de estas grietas se va configurando la imagen de las condenadas del mundo, esas cuyas vidas, cuyas historias han sido ocultas por el armazón feminista eurocentrado.

Referencias bibliográficas

AMORÓs, Celia. Tiempo de feminismo sobre feminismo, proyecto ilustrado y postmodernidad. Madrid : Cátedra, 1997.

El feminismo: Senda no transitada de la llustración. Isegoría (1), p. 139150, 1990. Disponible en: <https://e-mujeres.net/wpcontent/uploads/2016/08/el_feminismo_senda_no_transitada_de_la_ilustracion.pdf $>$.

Acceso: $13 / 03 / 2019$.

BAIRROS, Luísa. Nossos Feminismos Revisitado, en Revista Estudos Feministas, año 3, 2o semestre, p. 458-463, 1995.

BLASER, Mario. Un relato de globalización desde el Chaco. Popayán: Universidad del Cauca, 2013.

CARNEIRO, Sueli. Ennegrecer al Feminismo. Ponencia presentada en el seminario La situación de la Mujer negra en América Latina, desde una perspectiva de género, Sao Paulo, 2001.

CUMES, Aura. Multiculturalismo, género y feminismos: Mujeres diversas, luchas complejas en Andrea Pequeño (comp.), Participación y políticas de mujeres indígenas en América Latina. Quito: FLACSO sede Ecuador/ Ministerio de Cultura, p. 29-52, 2009.

DU BOIS, W.E.B. The Souls of Black Folk. New York: Bantam, 1989 [1903].

\footnotetext{
${ }^{3}$ A propósito de ello ver Celenis Rodriguez Moreno "Mujer y desarrollo: un discurso colonial”, El Cotidiano, 2014, y "Las políticas públicas de mujer y género: radiografía de una tecnología de género moderno colonial" en Los saberes múltiples y las ciencias sociales y políticas, tomó II, Universidad Nacional de Colombia, 2018, p. 321-338.
} 
DUSSEL, Enrique. Europa, modernidad y eurocentrismo. En Edgardo Lander (comp.), La colonialidad del saber: eurocentrismo y ciencias sociales. Perspectivas latinoamericanas. Buenos Aires: CLACSO, p. 41-53, 2000.

HOOKS, bell. Mujeres Negras. Dar forma a la teoría feminista. En Otras Inapropiables. Feminismos desde la Frontera. España: Traficantes de Sueños, 33-50, 2004.

ESPINOSA MIÑOSO, Yuderkys. Etnocentrismo y colonialidad en los feminismos latinoamericanos: Complicidades y consolidación de las hegemonías feministas en el espacio transnacional, en Revista Venezolana de Estudios de la Mujer, № 33, Vol. 14, p. 37-54, 2010.

La política sexual radical autónoma, sus debates internos y su crítica a la ideología de la diversidad sexual. En Pensando los feminismos en Bolivia. Conexión Fondo de Emancipación, Serie Foros 2, pp. 113-126. La Paz, 2012.

El futuro ya fue: una crítica a la idea del progreso en las narrativas de liberación sexo-genéricas y queer identitarias en Abya Yala. En Raúl Moarquech Ferrera-Balanquet (comp.), Andar erótico decolonial, Ediciones el Signo, colección El desprendimiento. Buenos Aires, pp. 21-39

Historizar las disputas, indagar las fuentes: hipótesis para pensar el movimiento de lesbianas en América Latina, Atlánticas - Revista Internacional de Estudios Feministas, 1, 1, 236-255, 2016

Hacia la construcción de la historia de un (des)encuentro: la razón feminista y la agencia antiracista y decolonial en abya yala, Praxis. Revista de filosofía n 75, pag 25-39, julio-diciembre, 2017.2 Disponible en: http://www.revistas.una.ac.cr/index.php/praxis/article/view/9966/12023>. Acceso: 10/03/2019.

Una crítica descolonial a la epistemología feminista crítica, Revista El Cotidiano Año 29, no 184, marzo - abril, p. 7-12, 2014. Disponible en <http://www.redalyc.org/pdf/325/32530724004.pdf>. Acceso: 4/03/2019.

CASTRO-GÓMEZ, Santiago (s/f) La filosofía latinoamericana como ontología crítica del presente. Temas y motivos para una "Crítica de la razón latinoamericana, Revista Dissens $n$. 4, S/F. Disponibel en: <http://www.ceapedi.com.ar/imagenes/biblioteca/libreria/156.pdf>. Acceso: 10/03/2019.

La hybris del punto cero ciencia, raza e ilustración en la nueva granada (17501816). Bogotá: Editorial Pontificia Universidad Javeriana, 2005.

Tejidos oníricos: movilidad, capitalismo y biopolítica en Bogotá (1910-1930). Bogotá: Editorial Pontificia Universidad Javeriana, 2009. 
Crítica de la razón latinoamericana -- 2a ed. -- Bogotá: Editorial Pontificia Universidad Javeriana, Instituto Pensar, COLCIENCIAS, 2011.

Michel Foucault: El oficio del genealogista. Conferencia dictada en el lanzamiento de Revista La Cicuta, revista de estudiantes del Departamento de Filosofía de la Universidad de los Andes, no 4, octubre, 2013. Disponible en: <https://www.youtube.com/watch?v=033YTK-t0zo>. Acceso: 9/03/2019.

FOUCAULT, Michel. ¿Qué es la ilustración?, en Saber y Verdad. Buenos Aires: ediciones La Piqueta, 1991.

FOUCAULT, Michel. Nietzsche, la genealogía, la historia en Microfísica del poder. Madrid: De La Piqueta, 1992.

GARGALLO, Francesca. Ideas feministas latinoamericanas. México, DF: Universidad Autónoma de la Ciudad de México, 2004.

GONÇALVEZ, Luis. La metodología genealógica y arqueológica de Michel Foucault en la investigación en psicología social. Montevideo: ficha CEUP, 2000. Disponible en:

$<$ http://www.fadu.edu.uy/estetica-diseno-ii/files/2015/06/transitos-de-una-psicologiasocial-genealogi\%CC\%81a-y-arqueologi\%CC\%81a.pdf> Acesso: 3/03/2019.

HARDING, Sandra (1986), The Science, Question in Feminism. Cornell: University Press, Ithaca, Nueva York, 1986.

¿Existe un método feminista?, versión traducida al español por Gloria Elena Bernal de: Is There a Feminist Method? In: Sandra Harding (ed.). Feminism and Methodology. Bloomington/ Indianapolis: Indiana University Press, 1987.

El feminismo, la ciencia y las críticas anti-iluministas. In: Marysa Navarro; Catharine R. Stimpson (comp.), Un nuevo saber. Los Estudios de Mujeres. Nuevas direcciones. Argentina: Fondo de Cultura Económica, p. 107-140, 2001.

¿Una filosofía de la ciencia socialmente relevante? Argumentos en torno a la controversia sobre el Punto de vista feminista. In: Blazquez Graf, Norma; Flores Palacios, Fátima; Ríos Everardo, Maribel (coord.), Investigación feminista: epistemología, metodología y representaciones sociales. México: UNAM, Centro de Investigaciones Interdisciplinarias en Ciencias y Humanidades: Centro Regional de Investigaciones Multidisciplinarias: Facultad de Psicología, p. 39-66, 2012.

HARTSOCK, Nancy. The Feminist standpoint: developing the ground for a specifically feminist historical materialism en Sandra Harding and Merrill B. Hintikka (eds.). Discovering Reality: Feminist Perspectives on Epistemology, Metaphysics, Methodology and Philosophy of Science. Dordrecht, The Netherlands: Reider Publishers, p. 283-310, 1983. 
HILL COLLINS, Patricia. La política del pensamiento feminista negro. En Marysa Navarro (comp.), ¿Qué son los estudios de mujeres?, México: Fondo de Cultura Económica, p. 253312, 1999.

KANT, Immanuel. Qué es la Ilustración en Filosofía de la Historia, Trad. Eugenio Imaz, México: Fondo de Cultura Económica, 1994 [1784].

MENDOZA, Breny (2010), La epistemología del sur, la colonialidad del género y el feminismo latinoamericano en Yuderkys Espinosa Miñoso (coord.), Aproximaciones críticas a las prácticas teórico-políticas del feminismo latinoamericano. Buenos Aires: en la frontera, $p$. 19-38.

MOHANTY, Chandra T. Bajo los ojos de Occidente. Academia feminista y discurso colonia en Rosalva Aída Hernández Castillo y Liliana Suárez Navaz (coord.). Descolonizar el Feminismo: Teorías y Prácticas desde los Márgenes. Madrid: Cátedra, p. 112-163, 2008a [1986].

De vuelta a "Bajo los ojos de Occidente": La solidaridad feminista a través de las luchas anticapitalistas en Rosalva Aída Hernández Castillo y Liliana Suárez Navaz (coord.), Descolonizar el Feminismo: Teorías y Prácticas desde los Márgenes. Madrid: Cátedra, p. 404$468,2008 b$ [2003].

PALERMO, Zulma. Conocimiento "otro" y conocimiento del otro en américa latina, Revista Estudios, № 21, otoño 2009, p. 79-90, 2008. Disponible en: $<$ https://revistas.unc.edu.ar/index.php/restudios/article/viewFile/13310/13506> Acceso: 27/02/2019.

QUIJANO, Aníbal. Colonialidad del poder, eurocentrismo y América Latina en Edgardo Lander (comp.) La colonialidad del saber: eurocentrismo y ciencias sociales. Perspectivas Latinoamericanas. Buenos Aires, Argentina: Consejo Latinoamericano de Ciencias Sociales (CLACSO), p. 225-242, 2000a.

Colonialidad y Clasificación Social, Journal of World Systems Research, Vol. VI, n. 2, Fall/Winter, Special Issue, Festschrift For Immanuel Wallerstein, Giovanni Arrighi and Walter L. Goldfrank, eds, Colorado, USA, p. 342-388, 2000b.

RODRÍGUEZ MORENO, Celenis. Mujer y desarrollo: un discurso colonial, El Cotidiano, n. 184, p.31-37, 2014. Disponible en: <https://www.redalyc.org/articulo.oa?id=32530724002>. Acesso: 10/01/2019.

Las políticas públicas de mujer y género: radiografía de una tecnología de género moderno colonial en Santiago Gómez Obando, Catherine Moore Torres y Leopoldo Múnera Ruiz (editores), Los saberes múltiples y las ciencias sociales y políticas, tomó II, p. 321-338. Bogotá: Universidad Nacional de Colombia, 2018.

SCOTT, Joan W. Experiencia, Revista La Ventana, n. 13, p. 42-73, 2000. 
SMITH, Dorothy E. Women's perspective as a radical critique of sociology, Sociological inquiry, 44(1), p. 7-13, 1974.

The everyday world as problematic: A sociology for women. Boston, Northeastern University Press, 1987.

El punto de vista (standpoint) de las mujeres: conocimiento encarnado versus relaciones de dominación, Temas de Mujeres, Revista del CEHIM, Año 8, n. 8, p. 5-27, 2012.

SOMMER, Doris. Una reivindicación de la doble conciencia, Estudios, Revista de Investigaciones Literarias y Culturales, Año 9, n. 17, ene-jun, Caracas, p. 85-91, 2001.

Sobre la autora

Yuderkys Espinosa Miñoso

Centro de Estudios de Género, INTEC/ Miembra fundadora del GLEFAS, Santo Domingo, República Dominicana. E-mail:espinosayuderkys@gmail.com.

La autora es la única responsable de la redacción del artículo. 